\title{
A Pilot Comparative Study of the Clarity and Assessability of the Drug Management Standards of Accreditation Canada and the US Joint Commission
}

\author{
Jordane Alemanni, Lionel Brisseau, Denis Lebel, Régis Vaillancourt, Louis Rocheleau, \\ and Jean-François Bussières
}

\begin{abstract}
Background: There are few data comparing the drug management standards of the US and Canadian agencies that accredit health care institutions.

Objective: To evaluate the clarity and assessability of criteria in the drug management standards adopted by Accreditation Canada and the Joint Commission (United States).

Methods: A pilot study was conducted to compare the clarity and assessability of the criteria listed in the 2 standards. Criteria that were common to the 2008 versions of the Canadian and US drug management standards were identified. A panel of 12 health care professionals was assembled to independently rate the clarity (i.e., clear or unclear) and the assessability (i.e., assessable or not assessable) of each statement, using a validated comparative grid.
\end{abstract}

Results: In total, there were 143 Canadian standards and 103 US standards. Sixty-two (43\%) of the 143 Canadian criteria could be directly paired with a US criterion, whereas 70 (68\%) of the 103 US criteria could be paired with one or more Canadian criteria. Six of the US criteria were paired with more than one Canadian criterion, and 12 of the Canadian criteria could be paired with more than one US criterion. Four of the 22 themes in the Canadian standards had no equivalent criteria in the US standards. Panel members from the pharmaceutical practice group evaluated the clarity and assessability of the Canadian criteria more severely than panel members from the nursing practice group: $86 \%$ versus $95 \%$ of individual ratings were deemed "clear" by these two groups, respectively $(p<0.001)$ and $64 \%$ versus $88 \%$ of individual ratings were deemed "assessable" $(p<0.001)$. There were no criteria that were considered unclear or unassessable by all of the panel members.

Conclusions: Few data are available on drug management standards and their impact on health care. A better understanding of these standards, as well as comparisons of Canadian standards with those of other countries, might help in determining their clarity and assessability. A larger-scale study is required to validate the observations reported here.

Key words: accreditation, standards, drug management, pharmacy practice

\section{RÉSUMÉ}

Contexte : : Il existe peu de données comparant les normes de gestion des médicaments des agences d'agrément des établissements de santé des États-Unis et du Canada.

Objectif : Déterminer la clarté et l'évaluabilité des critères des normes de gestion des médicaments édictés par Agrément Canada et par la Joint Commission des États-Unis.

Méthodes : Une étude pilote a été menée pour comparer la clarté et l'évaluabilité des critères énumérés dans les deux normes. Les critères communs aux versions de 2008 des normes de gestion des médicaments canadiennes et étasuniennes ont été appariés. Un comité de 12 professionnels de la santé a été mis sur pied pour juger de façon indépendante de la clarté (c.-à-d. norme claire ou équivoque) et de l'évaluabilité (c.-à-d. évaluable ou non évaluable) de chaque énoncé, au moyen d'une grille comparative validée.

Résultats : Un total de 143 normes canadiennes et de 103 normes étasuniennes ont fait l'objet de l'étude. Soixante-deux (43\%) des 143 critères canadiens ont pu être appariés directement à un critère étasunien alors que $70(68 \%)$ des 103 critères étasuniens ont pu être appariés à au moins un critère canadien. Six des critères étasuniens ont été appariés à plus d'un critère canadien et 12 des critères canadiens ont pu être appariés à plus d'un critère étasunien. Quatre des 22 thèmes des normes canadiennes n'avaient aucun critère équivalent dans les normes étasuniennes. Les membres du comité appartenant au groupe de pratique pharmaceutique ont jugé la clarté et l'évaluabilité des critères canadiens plus sévèrement que les membres du comité appartenant au groupe de soins infirmiers : $86 \%$ contre $95 \%$ des évaluations individuelles ont été respectivement considérées « claires " par ces deux groupes $(p<0.001)$ et $64 \%$ contre $88 \%$ des évaluations individuelles ont été jugées " évaluables " $(p<0.001)$. Aucun des critères n'est apparu équivoque ou non évaluable à tous les membres du comité.

Conclusions : Il existe peu de données sur les normes de gestion des médicaments et leur incidence sur les soins de santé. Une meilleure compréhension de ces normes et la comparaison des normes canadiennes avec celles d'autres pays pourraient aider à mieux juger de leur clarté et 


\section{Can J Hosp Pharm 2011;64(2):116-123}

de leur évaluabilité. Une étude de plus grande envergure est nécessaire pour valider les présents résultats.

Mots clés : agrément, normes, gestion des médicaments, pratique de la pharmacie

[Traduction par l'éditeur]

\section{INTRODUCTION}

$\mathrm{W}^{\prime}$ ith the implementation of a hospital system in North America at the beginning of the 20th century, the American College of Surgeons, of which Canada was an active member, undertook to develop a program of standardization of care for hospitals. The College published the first version of its minimal standard for hospitals in $1917 .{ }^{1}$

In 1952, the American College of Surgeons joined with the American College of Physicians, the American Hospital Association, the American Medical Association, and the Canadian Medical Association to form a stand-alone, notfor-profit agency (the Joint Commission on Accreditation of Hospitals), which was to be responsible for ensuring the management of a voluntary accreditation program. In 1953, the Canadian Hospital Association, the Canadian Medical Association, the Royal College of Physicians and Surgeons of Canada, and the Association des médecins de langue française du Canada set up a Canadian organization, the Canadian Commission on Hospital Accreditation, which in 1958 became the Canadian Council on Hospital Accreditation. ${ }^{1}$ As early as 1967, within the standards of this organization, there were already 5 statements included in the chapter on pharmacy, covering the role of the hospital pharmacist, storage of medications, pharmaceutical control in hospitals, error prevention, drug control, and abnormal drug reactions. ${ }^{2}$

The Canadian organization extended its influence by adopting standards for short-term care, long-term care, and psychiatric and rehabilitation institutions and in 1988 became the Canadian Council on Health Facilities Accreditation. Beginning in the 1980s, the organization had become interested not only in structures but also processes and some outcomes. One of the Council's standards of practice guided evaluation of the organization and activities of a pharmacy department, under 7 themes: rationale, aims, and objectives; pharmaceutical supervision; policies and procedures; human and material resources; direction, professional development, and training; pharmaceutical care; and evaluation of practice. In 1995, the organization became the Canadian Council on Health Services Accreditation, and began encouraging patient-focused health care and services. Existing standards were reviewed and those focused on the pharmacy department became integrated within population-based standards. In 2002, the Canadian organization obtained certification from the International Society for Quality in Health Care. ${ }^{1}$

Publication of the report To Err is Human: Building a Safer Health System ${ }^{3}$ by the US Institute of Medicine in 1999 provoked intensification of the development of programs to enhance the safety of health care and health care services. In 2005, in accord with this movement in favour of safety, the Canadian Council on Health Services Accreditation developed its Required Organizational Practices and integrated them into its standards.

In 2008, the organization changed its name again to become Accreditation Canada. It then renewed its methodology by proposing the Qmentum program, which is built on ongoing enhancements to quality care and patient safety. This renewal was illustrated by a return to a so-called transversal standard for managing medications. This standard, which focuses on the medication-use system (i.e., the 54 steps in medication therapy, encompassing drug selection and purchase, prescription, validation, preparation, dispensing, administration, and disposal) within any institution, was prepared with the help of the Canadian Society of Hospital Pharmacists and the Institute for Safe Medication Practices Canada (ISMP Canada), taking into account the criteria of the US Institute for Safe Medication Practices (ISMP), as outlined in the Medication Safety Self-Assessment Tool for Automated Dispensing Cabinets. ${ }^{4}$ As an example, this tool was designed to help hospitals to assess their medication safety practices related to the use of automated dispensing cabinets, allowing institutions to identify opportunities for improvement and to compare their experiences with the aggregate experience of demographically similar hospitals.

In its 2009 annual report, Accreditation Canada reported that 1063 health care institutions throughout the Canadian health care network had completed the accreditation process in 2009 (including long-term care facilities [35\% of institutions accredited], acute care facilities [16\%], and correctional services facilities $[16 \%]) .5$ 
As of September 30, 2010, the Qmentum program consisted of 48 standards, 4 of which were system-wide (including the standard for managing medications), 6 of which were population-based, and 38 of which referred to service excellence. The standard on drug management had 7 subsections: working together to promote medication safety, carefully selecting and procuring medications, properly labelling and storing medications, appropriately ordering and transcribing medications, accurately preparing and dispensing medications, safely administering medications to clients, and monitoring quality and achieving positive results. These subsections were divided into 22 themes with a total of 143 individual compliance criteria. The proposed normative framework for the overall accreditation process had 35 Required Organizational Practices, including some with a direct effect on the medication-use system, such as medication reconciliation on admission; medication reconciliation at the time of referral and transfer; prospective analysis related to the safety of patients over the year preceding the accreditation process and implementation of appropriate enhancements and changes; use of at least 2 client identifiers before providing any kind of service or procedure; development and implementation of a list of abbreviations, symbols, and dose designations that must not be used; assessment and restriction of the availability of heparin and narcotic (opioid) products; and withdrawal of high-dose formats.

Few data are available for comparisons of the medication management standards used by the US and Canadian agencies that accredit health care institutions. As early as 2006, the US Joint Commission launched the Standards Improvement Initiative to improve its own standards, particularly in terms of language (e.g., to avoid jargon unique to the Joint Commission and to use the active voice) and structure (e.g., to improve the logical sequence of criteria and to avoid compound, redundant, or similar criteria). ${ }^{6}$ In addition, the International Society for Quality in Health Care published criteria for the evaluation of accreditation agencies, which examine the content and formulation of agencies' standards (e.g., criterion 5.8: "The wording of the standards is clear and unambiguous"; criterion 6.1: "There is a transparent system for rating an organization's performance on each standard, criterion or element").

The aim of this descriptive study was to evaluate the clarity and assessability of the criteria for drug management standards adopted by the Joint Commission and Accreditation Canada. A secondary aim was to directly compare, in the context of a pilot study, the clarity and assessability of criteria in the 2 standards.

\section{METHODS}

The 2008 version of each drug management standard was used for this analysis. ${ }^{89}$ The Canadian standard had 143 individual criteria," and the US standard had 103 individual criteria. ${ }^{8}$ Using these 2008 versions, the research team (2 pharmacy research assistants, both of whom were pharmacy residents [J.A., L.B.], and 1 research pharmacist, the director of a pharmacy department [J.-F.B.]) established pairing of the criteria common to the 2 standards. One of the pharmacy research assistants performed the initial pairing, and the second pharmacy research assistant validated the proposed pairing. Any discrepancies were discussed and resolved by consensus, under the supervision of the research pharmacist. All three of these individuals were closely involved in the medication-use system, and had participated in previous accreditation visits in 2008.

A panel of 12 clinicians was recruited to perform the evaluations of clarity and assessability: the research team (the research pharmacist and pharmacy research assistants identified above), a risk-management pharmacist, an institutional risk manager, 6 nursing advisors, and a visiting pharmacist (from Accreditation Canada). The panel members were organized into 2 categories: pharmaceutical practice (i.e., all panel members except the nursing advisors) and nursing practice (the nursing advisors). For the analytical purposes, the institutional risk manager was included in the pharmaceutical practice category.

A comparative grid was created and validated specifically for the purposes of this study. For each criterion in the Canadian and US standards, each panel member was asked to rate the clarity of the statement (i.e., whether it was clear or unclear) and its assessability (i.e., whether it was assessable or unassessable). No detailed definition of "clarity" was provided. However, written and verbal instructions to panel members indicated that a criterion could be considered unclear if the panel member did not understand what it meant. A criterion was considered unassessable if the panel member did not believe that he or she could evaluate an institution's or a department's conformity of practice with the criterion. A criterion that was deemed unclear was by definition unassessable. However, if required, any criteria rated as being both unclear and assessable were manually rerated as unassessable. Panel members were also asked to formulate a compliance test for each of the Canadian criteria that they deemed to be assessable.

The panel members were recruited in person or by telephone, and instructions were sent by e-mail. Each panel member submitted a written copy of his or her annotated grid, and the data were compiled in an MS Excel (Microsoft, Seattle, Washington) spreadsheet.

Descriptive statistical analyses were performed. With the terminology of the Canadian standard as the baseline, the proportion of Canadian criteria with US equivalents was determined for each theme. The proportion of US criteria with 
Canadian equivalents was also determined, according to the Canadian themes. In addition, the proportions of criteria that were deemed clear and assessable were determined according to the 2 types of panel member (pharmaceutical practice, nursing practice). $\chi^{2}$ testing was used to compare the proportions of clear or assessable criteria between the 2 groups of panel members (pharmaceutical practice versus nursing practice) for the Canadian and US criteria. $\chi^{2}$ testing was also used to compare the proportions of clear or assessable criteria between Canadian and US criteria, for each group of panel members.

For data presentation, the themes were organized according to the key steps of the medication-use system. Finally, criteria with clarity or assessability scores below $66 \%$ were identified. This arbitrarily defined threshold described a reasonable level of clarity and assessability (i.e., two-thirds). Values of $p$ less than 0.05 were considered significant.

\section{RESULTS}

The 12 panel members participating in this pilot study assessed the clarity and assessability of the 2008 versions of the Canadian and US drug management standards, in September 2010. All of the panel members had at least 5 years' experience as professionals in the Canadian health care system.

Sixty-two (43\%) of the 143 Canadian criteria could be directly paired with a US criterion, whereas $70(68 \%)$ of the 103 US criteria could be paired with one or more Canadian criteria (Table 1). Six of the US criteria were paired with more than one Canadian criterion, and 12 of the Canadian criteria could be paired with more than one US criterion. Four of the 22 themes in the Canadian standard had no equivalent criteria in the US standard (Table 1).

Panel members generated a total of 1716 ratings for the Canadian standard (143 criteria $\times 12$ panel members) and a total of 1236 ratings for the US standard (103 criteria $\times 12$ panel members). Analysis of these individual ratings revealed a total of 277 unclear ratings: 168 for the Canadian standard and 109 for the US standard (Table 2). Of these "unclear" ratings, 12 were initially combined with a rating of "assessable"; these were recoded as "unassessable", as described in the Methods section.

The pharmaceutical practice members of the panel evaluated the clarity and assessability of the Canadian criteria more severely than the nursing practice members: $86 \%$ versus $95 \%$ of individual ratings were deemed "clear" by these two groups ( $p<0.001$ ) and $64 \%$ versus $88 \%$ of individual ratings were deemed "assessable" ( $p<0.001)$. Although clarity ratings for all panelists did not differ significantly for the Canadian and US criteria ( $90 \%$ versus $91 \% ; p=0.41$ ), assessability ratings were lower for the Canadian criteria (76\% versus 83\%; $p<0.001)$ (Table 2). A total of $41 \%(101 / 246)$ of all criteria from both standards were considered clear by all of the panel members, and $13 \%(33 / 246)$ were considered assessable by all of the panel members. There were no criteria that were considered unclear or unassessable by all of the panel members.

In addition to the individual ratings, an overall status of "clear" or "assessable" was attributed to any criterion for which at least two-thirds of the respondents (i.e., $\geq 8$ of 12) assigned a rating of "clear" or "assessable", respectively (not reported in Table 2). On this basis, 95\% (136/143) of the Canadian criteria and 99\% (102/103) of the US criteria were deemed "clear" ( $p=0.18)$. Also, 78\% (111/143) of the Canadian criteria and $96 \%(99 / 103)$ of the US criteria were deemed "assessable" ( $p<0.001)$. This supported the general indication that panel members perceived the Canadian criteria as less assessable than the US criteria. The profile of clarity and assessability of criteria in the Canadian and US drug management standards, according to the steps in the medication-use system, appears in Appendix 1 (available online at www.cjhponline.ca/index.php/cjhp/issue/view/80/showToc). The profile of 23 criteria from the Canadian drug management standard with a rating of "clear" or "assessable" by less than two-thirds of panel members, in increasing order of assessability is presented in Appendix 2 (available online at www.cjhp-online.cal index.php/cjhp/issue/view/80/showToc).

Finally, the grids completed by panel members allowed qualitative identification of the main test proposed for verifying compliance with criteria in the Canadian standard. A majority of panel members suggested that compliance be verified on the basis of an institution's internal documents (e.g., policies and procedures, lists, forms, reports, flow charts, work programs, medication reconciliation forms, drug administration registers, and incident reports) and use of these documents according to institutional policies, as well as adequate use of communication tools (e.g., warnings, e-mail messages, briefing notes, intranet). In a number of cases, panel members stressed that the criteria could be adequately assessed only by means of tracers, practice audits, or sampling. Several of the proposed tests would rely on indirect observation of the premises, as well as observation of staff in action or even patients. Among the general comments provided by panel members, nurses indicated their preference for shorter formulation of criteria.

\section{DISCUSSION}

Accreditation is defined as a public recognition of the achievement of accreditation standards by a health care organization, demonstrated through an independent external peer assessment of that organization's level of performance in relation to the standards. ${ }^{10-12}$ Given the complexity of health care and its effect on health outcomes, the importance of renewing the accreditation of health care agencies periodically has been acknowledged. ${ }^{13-15}$ In addition, most accreditation programs have migrated from an approach based on structures 
Table 1. Comparison of Equivalent Criteria between US and Canadian Standards

\section{Canadian Theme}

\begin{tabular}{cc}
\multicolumn{2}{c}{ Canadian Criteria9 } \\
\hline No. of & No. (\%) \\
Criteria & Paired \\
& with US \\
& Criteria
\end{tabular}

1. The organization's pharmacists and pharmacy's staff work closely with prescribing medical professionals and other service providers to support safe medication use.

2. The organization maintains an up-to-date and evidence-based list of available medications.

3. The organization minimizes the medications it procures and has available.

4. The organization reduces the possibility of errors with drug product nomenclature, labeling, and packaging.

5. The organization clearly and legibly labels all drug concentrations.

6. The organization provides suitable space for drug storage in pharmacies and client/unit medication areas.

7. The organization carefully selects stock drugs for each client area.

8. The organization stores hazardous chemicals away from clients, service providers, and drug preparation areas.

9. The organization maintains accessible and up-to-date client information.

10. The organization communicates drug orders and other drug information in a standardized way.

11. The pharmacy reviews all prescriptions or medication orders for accuracy and appropriateness.

12. The pharmacy prevents contamination when preparing medications.

13. The pharmacy dispenses medications in a safe, accurate, and timely way.

14. Where is no internal pharmacy or when the pharmacy is closed, the organization has a system to safely dispense medications.

15. The pharmacy transports medication in a safe, secure, and timely manner way [sic].

16. The organization educates clients about their medications and delivery devices, and ways to prevent errors.

17. The organization follows a process to allow and monitor clients' self-administration of their medications.

18. The organization safely and accurately administers medications.

19. The organization reduces the risk of error through careful procurement, maintenance, use, and standardization of medication delivery devices.

20. The organization monitors clients following medication administration.

21. The organization has a coordinated risk management program to reduce medicationrelated errors and sentinel events.

22. The organization regularly monitors and evaluates the quality of the medication management and pharmacy system.

1 (10)

US Criteria $^{8}$

\begin{tabular}{ccc}
$\begin{array}{c}\text { No. of } \\
\text { Criteria }\end{array}$ & $\begin{array}{c}\text { No. (\%) } \\
\text { Paired } \\
\text { with Canadian } \\
\text { Criteria }\end{array}$ & $\begin{array}{c}\text { No. (\%) of All } \\
\text { Criteria Paired } \\
\text { with Other } \\
\text { Standard }\end{array}$ \\
\hline 2 & $1 \quad(50)$ & $2 / 12(17)$
\end{tabular}

6 (75)

$5 \quad(56)$

$0 \quad(0)$

1 (25)

$5 \quad(71)$

$5 \quad(71)$

7

5

1 (20)

3 (75)

8 (73)

2 (33)

4 (44)

3 (43)

7

3 (100)

3

6

2 (33)

5

$0 \quad(0)$

4

2 (50)

6

6 (100)

$12 / 14$ (86)*

9

6 (67)

$11 / 18$ (61)*

0

0

(0)

0/4

(0)

2/8 (25)

$11 / 16$ (69)*

$9 \quad 6 \quad(67) \quad 11 / 16(69)$ *

10

$10(100)$

15/17 (88)*

2/6 (33)

1 (100)

$6 / 7(86)^{*}$

3 (100)

$16 / 23$ (70)*

4/8 (50)

$6 / 13(46)^{*}$

$6 / 12 \quad(50)$

$7 / 11$ (64)*

4/9 (44)

$0 / 5 \quad(0)$

$5 / 7(71)^{*}$

$\begin{array}{rrrrrrrr}10 & 4 & (40) & 14 & 7 & (50) & 11 / 24 & (46) * \\ 7 & 0 & (0) & 0 & 0 & (0) & 0 / 7 & (0)\end{array}$

3

3 (100)

3

2 (67)

$5 / 6(83)^{*}$

10

$0 \quad(0)$

0

$0 \quad(0)$

0/10

(0)

6

4 (67)

$8 / 10(80)^{*}$

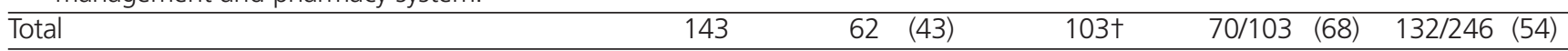

*Six of the US criteria could be paired with more than one Canadian criterion, and 12 of the Canadian criteria could be paired with more than one US criterion.

tBecause one of the US criteria appeared under more than one theme, the sum of the values in the column of US criteria is greater than 103 , the actual total number of US criteria. 
Table 2. Clarity and Assessability of Criteria of the Canadian and US Drug Management Standards, by Type of Panel Member*

\begin{tabular}{|c|c|c|c|c|c|c|}
\hline \multirow[b]{2}{*}{ Panel Member Type } & \multicolumn{3}{|c|}{ Clarity } & \multicolumn{3}{|c|}{ Assessability } \\
\hline & $\begin{array}{c}\text { Canadian } \\
\text { Criteria } \\
n(\%)\end{array}$ & $\begin{array}{c}\text { US Criteria } \\
n(\%)\end{array}$ & $p$ Valuet & $\begin{array}{c}\text { Canadian } \\
\text { Criteria } \\
n(\%)\end{array}$ & $\begin{array}{c}\text { US Criteria } \\
n(\%)\end{array}$ & $p$ Valuet \\
\hline Pharmaceutical practice & $\begin{array}{l}735 / 858 \\
(86 \%) \neq\end{array}$ & $\begin{array}{c}574 / 618 \\
(93 \%) \S \\
\end{array}$ & $<0.001$ & $\begin{array}{l}549 / 858 \\
(64 \%) \emptyset \\
\end{array}$ & $\begin{array}{l}482 / 618 \\
(78 \%)^{\star *} \\
\end{array}$ & $<0.001$ \\
\hline Nursing practice & $\begin{array}{l}813 / 858 \\
(95 \%) \neq\end{array}$ & $\begin{array}{l}553 / 618 \\
(89 \%) \S\end{array}$ & $<0.001$ & $\begin{array}{l}758 / 858 \\
(88 \%) \emptyset\end{array}$ & $\begin{array}{l}539 / 618 \\
(87 \%)^{* *}\end{array}$ & 0.57 \\
\hline$\overline{A l l}$ & $\begin{array}{c}1548 / 1716 \\
(90 \%)\end{array}$ & $\begin{array}{c}1127 / 1236 \\
(91 \%)\end{array}$ & 0.41 & $\begin{array}{c}1307 / 1716 \\
(76 \%)\end{array}$ & $\begin{array}{c}1021 / 1236 \\
(83 \%)\end{array}$ & $<0.001$ \\
\hline
\end{tabular}

*Each of the 6 members in each of the 2 groups (pharmaceutical practice, nursing practice) evaluated a total of 143 Canadian criteria (for a total of 858 data points per group) and a total of 103 US criteria (for a total of 618 data points per group)

†For comparison between the Canadian and US drug management standards ( $\chi^{2}$ test). $\neq p<0.001$ for difference between pharmaceutical practice experts and nursing practice experts in evaluation of clarity of the Canadian standard ( $\chi^{2}$ test).

$\S p=0.045$ for difference between pharmaceutical practice experts and nursing practice experts in evaluation of clarity of the US standard ( $\chi^{2}$ test).

\$p $<0.001$ for difference between pharmaceutical practice experts and nursing practice experts in evaluation of assessability of the Canadian standard ( $\chi^{2}$ test).

${ }^{*} p<0.001$ for difference between pharmaceutical practice experts and nursing practice experts in evaluation of assessability of the US standard ( $\chi^{2}$ test).

and processes toward a patient-focused approach. ${ }^{16}$ Although accreditation is voluntary in many countries, some researchers and health care decision-makers think that the process should be mandatory, to help ensure the quality of health care. ${ }^{17}$ In Canada, only health care institutions in Quebec are required to hold accreditation from a recognized agency such as Accreditation Canada, but some other provinces have adopted laws relating to the safety of health care services.

To the authors' knowledge, this is the first descriptive and comparative analysis of the drug management standards of the two North American accreditation agencies: the Joint Commission in the United States and Accreditation Canada in Canada. These agencies have a common past and function in health care systems that are similar in many ways, but there are notable similarities and differences between these agencies in terms of their views of the medication-use system. The US standard used by the Joint Commission and evaluated in this study has been in place since 1953 and is now updated annually. Given the involvement of ISMP Canada in development of the Canadian standards and given the close relationship between ISMP Canada and its US counterpart (ISMP), it is reasonable to think that Accreditation Canada drew on the US standard when writing its drug management standard, which has been in effect since January 2008. However, the current study revealed limited crossover, in that fewer than half of the Canadian criteria (43\%) had a US equivalent. This overlap is probably closely linked to the focus of Accreditation Canada and its Qmentum program on the delivery of safe health care and the higher number of Canadian criteria. In particular, 26 criteria from 4 themes in the Canadian standard (themes 4, 16, 19, and 21) could not be paired with criteria in the US standard, and all of these themes relate to error prevention or risk management (Table 1).

The process of writing criteria for standards is undoubtedly difficult. Using data from the Working Group on Evaluation Criteria and Ratings for Public Evaluation, the World Bank described the essential characteristics of a good assessment: pertinence, consistency, efficiency, efficacy, impact, durability, and reproducibility. ${ }^{18,19}$ In addition, the presence of objectively verifiable indicators is a precondition for success. These indicators should be measurable, based on facts, appropriate, and sound. ${ }^{18,19}$ More specific to the field of health care, the International Society for Quality in Health Care and the World Health Organization proposed rules for formulating standards that are valid and credible, with effects that are measurable, while taking into account, among other things, the following criteria: use of current, fact-based knowledge and data; expected level of application; specificity, measurability, and implementation according to a precise timetable; application of a valid measurement method; formulation in plain language, without jargon; use of the active voice (e.g. "The institution offers..." or "The caregivers support ..."); independence of expected results from resources (i.e., the indicator may be practically attained regardless of whether resources are abundant or scarce); and unambiguous statement, without terminology such as "should" or "may" (which express results that are desired but not stipulated). ${ }^{7,20}$

In this study, $90 \%$ of individual clarity ratings assigned for Canadian criteria and $91 \%$ of those assigned for US criteria indicated that the criteria were clear, as evaluated by panel 
members from pharmaceutical and nursing practice. This result is reassuring but underlines the importance of attempting to prospectively clarify criteria that are deemed unclear by institutions participating in the accreditation process. In terms of transparency and improving assessment criteria, accreditation agencies have introduced a question-and-answer mechanism aimed at specifying the interpretation and application of the various standards (e.g., "Ask the Joint Commission"). ${ }^{21}$ This approach must be encouraged. In this study, the proportions of individual assessability ratings indicating that the criteria were assessable were much lower than the corresponding proportions for clarity ( $76 \%$ for the Canadian criteria and $83 \%$ for the US criteria). Comparisons of the wording of the Canadian and US criteria revealed that the wording of the US criteria was often more precise, especially in terms of the nature of the assessed activity (e.g., the presence and availability of available emergency drugs), the frequency of the assessed activity (e.g., at least annually versus periodically), the distinction between structure indicators and findings (e.g., presence of a policy and procedure and verification of its implementation status versus presence of a policy and procedure). Ideally, all criteria should be clear and assessable. For nearly one-quarter of the individual ratings of Canadian criteria, panel members deemed the criterion unassessable. In a supplementary analysis, the proportions of criteria deemed clear or assessable by at least two-thirds of panel members were slightly higher.

In terms of differences in perceptions of clarity and assessability, the panel members from pharmaceutical practice evaluated the clarity and assessability of the criteria more severely that did panel members from the nursing practice group. This may reflect the fact that panel members from pharmaceutical practice are generally more aware of the medication-use system and the difficulties of assessing practice in this area.

On the other hand, the drug management standard focuses on pharmaceutical practice (rather than nursing practice), and participants in the pharmaceutical practice group may have been less inclined to undergo such assessments themselves than participants from the nursing practice group would have been, because the medication-use system is at the heart of their practice and profession. As such, they may have been tempted to designate certain criteria as "unassessable" in reaction to the assessment exercise, rather than the actual ability to evaluate the criteria. For example, Canadian criterion 3.3 ("To help differentiate products with similar labeling/packaging, the organization obtains products from different manufacturers") was considered unassessable by the entire pharmaceutical practice group, whereas it was considered assessable by all of the nursing practice participants. It appeared that participants from the nursing practice group assumed that the selection and acquisition of products systematically or frequently includes a comparison of labelling to restrict similarities. In fact, given markets, stock shortages, and acquisition processes, it is difficult to apply this rule and even more difficult to assess compliance with it.

Interestingly, among the written annotations of panel members, the nurses preferred shorter criteria, which they incidentally deemed to be clearer. In contrast, the pharmacists preferred longer and more detailed criteria, which would presumably help to provide more clarity and assessability.

As for the various compliance tests proposed by respondents, a certain number evoked various types of direct observations, audits, or tracer cases. However, it can be difficult to interpret the findings of such tests objectively, given factors related to the person being observed or questioned and his or her possible "preparation" for such an assessment.

Although the results of this pilot study indicated that some criteria are unclear and unassessable, it should be remembered that Accreditation Canada's site visit teams undergo training before they use the criteria in conducting the accreditation process. Also, the results of this pilot study suggest that continuous review of the criteria is necessary and that such review should be undertaken in collaboration with key stakeholders, including nurses and pharmacists in practice.

This study had a number of limitations. The panel of clinicians was made up of professionals with at least 5 years' experience and at least one exposure to Accreditation Canada's Qmentum program, but the study did not take into consideration their expertise in relation to the accreditation process. Also, the panel members had no exposure to the US standard through a formal accreditation process. The scoring might have differed if the panel had included professionals more closely involved in redaction or modification of accreditation criteria.

The measure used for clarity and assessability was based on a dichotomous scale (yes/no), which was deemed preferable over a spontaneous evaluation by panel members. Each assessment was based on the panel member's understanding of the criterion and his or her particular expertise. Such an evaluation is a good reality test, as typical clinicians would understand and react to a broad range of these criteria within a health care setting. Also, it is important to note that other relevant aspects of the medication-use system are covered by other norms within the Qmentum program that were not included in this analysis. A broader evaluation of all relevant criteria included in all norms would have provided a more complete picture. Although 4 of the 22 themes in the Canadian standard had no equivalent criteria in the US standard, there was no investigation to determine if these themes were captured in a US standard other than the medication management standard. Finally, the small size of the panel prevented us from making general statements about the findings on a larger scale. Nevertheless, the panel offered a professional perspective that may contribute to better integration of the norm by hospital 
pharmacists in their practice. In terms of grouping the panel members, the risk manager could have been grouped with nurses, rather than the pharmacists, but we believe that this person shared a common perspective of the medication-use system with the pharmacists, by virtue of being involved in the analysis of drug errors at the institutional level.

\section{CONCLUSIONS}

Few data are available about drug management standards and their impact on health care. A better understanding of these standards and comparisons with the standards of other countries may help in evaluating their clarity and assessability. A larger-scale study is required to validate these observations.

\section{References}

1. History. Ottawa (ON): Accreditation Canada; [cited 2010 Oct 3]. Available from: www.accreditation.ca/en/content.aspx?pageid=38\& langType $=1033$

2. Compendium des guides pour l'accréditation des hôpitaux. Toronto $(\mathrm{ON})$ : Conseil canadien d'accréditation des hôpitaux; 1967.

3. Kohn LT, Corrigan JM, Donaldson MS, editors. To err is human: building a safer health system. Washington (DC): National Academy Press, Institute of Medicine; 1999 [cited 2010 Oct 3]. Available from: www.nap.edu/ openbook.php?record_id $=9728$

4. ISMP medication safety self-assessment ${ }^{\circledR}$ for automated dispensing cabinets. Horsham (PA): Institute for Safe Medication Practices; 2009 [cited 2010 Dec 3]. Available from: www.ismp.org/selfassessments/ADC/ survey.pdf

5. Annual report 2009. Ottawa (ON): Accreditation Canada; 2009 [cited 2010 Oct 3]. Available from: www.accreditation.ca/news-and-publications/ publications/annual-report/

6. Standards improvement initiative: an overview. Oak Brook (IL): The Joint Commission Resources; 2008 [cited 2010 Oct 3]. Available from: www.jcrinc.com/Standards-Improvement-Initiative/

7. International principles for healthcare standards. 3rd ed. Melbourne (Australia): International Society for Quality in Health Care; 2007 [cited 2010 Oct 3]. Available from: www.akaz.ba/Standardi/Dokumenti/ ISQuaIAPPrinciplesV3.pdf

8. Medication management [standard]. In: Hospital accreditation standards. Oak Brook (IL): The Joint Commission on Accreditation of Healthcare Organizations; 2008.

9. Managing medications [standard]. Ottawa (ON): Accreditation Canada; [cited 2010 Oct 3]. Available from: www.accreditation.ca/accreditationprograms/qmentum/standards/managing-medications/

10. Nickin W, Dickson S. The value and impact of accreditation in health care: a review of the literature. Ottawa (ON): Accreditation Canada; 2008 [updated 2009 Jun; cited 2010 Oct 3]. Available from: www. accreditation.ca/uploadedFiles/Value\%20of\%20Accreditation_EN.pdf

11. Shaw CD. Toolkit for accreditation programmes. Some issues in the design and redesign of external health care assessment and improvement systems. Melbourne (Australia): International Society for Quality in Health Care; 2004 [cited 2010 Oct 3]. Available from: http:// ps4h.org/docs3/Shaw\%202005\%20toolkit.pdf

12. Rooney AL, Van Ostenberg PR. Licensure, accreditation, and certification: approaches to health service quality. Quality Assurance Project 38. Bethesda (MD): Center for Human Services; 1999.

13. Shaw CD. External assessment of health care. BMJ 2001;322(7290): 851-854.

14. Jovanovic B. Hospital accreditation as method for assessing quality in healthcare. Arch Oncol 2005;13(3):156-157.

15. Shaw CD. Evaluating accreditation. Int J Qual Health Care 2003; 15(6):455-456.
16. Scrivens E. Putting continuous quality improvement into accreditation: improving approaches to quality assessment. Qual Health Care 1997; 6(4):212-218

17. Touati N, Pomey MP. Accreditation at a crossroads: Are we on the right track? Health Policy 2009;90(2-3):156-165.

18. Eriksson J. Review of good practice and processes for evaluation of public sector operations by MDBs. Prepared for Working Group on Evaluation Criteria and Ratings for Public Evaluation. Washington (DC): Multilateral Development Bank, Evaluation Cooperation Group; 2001 [cited 2010 Oct 3]. Available from: www.adb.org/evaluation/wgec.pdf

19. Introduction à l'évaluation de programme [PowerPoint presentations] Washington (DC): World Bank; [cited 2010 Oct 3]. Available from: http://siteresources.worldbank.org/PGLP/Resources/French_Module6 .ppt and http://siteresources.worldbank.org/PGLP/Resources/French_ Module8.ppt

20. Normes de qualité des soins de l'infection à VIH : outils de l'évaluation et de l'amélioration de la qualité et d'accréditation des services de santé. Rapport d'une consultation OMS sur l'accréditation des services de santé chargés des soins de l'infection à VIH. Genève (Switzerland): World Health Organization; 2004 [cited 2010 Oct 3]. Available from: www.who.int/hiv/pub/prev_care/standardsquality_fr.pdf

21. Rich DS. Ask The Joint Commission: questions and answers about the 2004 medication management standards. Hosp Pharm 2003; 38(12):1175-1179.

Jordane Alemanni is a pharmacy resident with the Université de Toulouse III, Paul Sabatier, Toulouse, France. She is also a Research Assistant with the Research Unit in Pharmacy Practice, CHU SainteJustine, Montréal, Quebec.

Lionel Brisseau is a pharmacy resident with the Université de Nantes, Nantes, France. He is also a Research Assistant with the Research Unit in Pharmacy Practice, CHU Sainte-Justine, Montréal, Quebec.

Denis Lebel, BPharm, MSc, FCSHP, is Assistant Director of the Department of Pharmaceutical Care, Education and Research in the Pharmacy Department, CHU Sainte-Justine, Montréal, Quebec.

Régis Vaillancourt, BPharm, PharmD, FCSHP, is Director of Pharmacy, Children's Hospital of Eastern Ontario, Ottawa, Ontario. He is also an Associate Editor with the CHP.

Louis Rocheleau, MA, is Interim Coordinator of Quality and Risk Management, Department of Quality, Safety and Risks, CHU Sainte-Justine, Montréal, Quebec.

Jean-François Bussières, BPharm, MSc, FCSHP, is Director of the Pharmacy Department and Research Unit in Pharmacy Practice, CHU SainteJustine, and Clinical Professor, Faculty of Pharmacy, Université de Montréal, Montréal, Quebec.

\section{Address correspondence to:}

Jean-François Bussières

Pharmacy Department

Centre hospitalier universitaire Sainte-Justine

3175, chemin de la Côte Sainte-Catherine

Montréal QC H3T 1C5

e-mail: jf.bussieres@ssss.gouv.qc.ca

\section{Acknowledgements}

The authors thank Karine Bouchard, Stéphanie Duval, Nathalie Fillon, Geneviève Harbec, Catherine Hogue, and Marie-Pierre Pelletier, clinical nurse specialists, at the Direction des soins infirmiers, $\mathrm{CHU}$ Sainte-Justine, who served as panel members, and Cynthia Tanguay, $\mathrm{BSC}, \mathrm{MSc}$, research assistant, Research Unit in Pharmacy Practice, $\mathrm{CHU}$ Sainte-Justine, for revision of the manuscript.

This manuscript has been shared with Accreditation Canada, which has authorized the publication of specific criteria as examples in the context of this study. 